\title{
STRATEGI HUMAN CAPITAL BANK MANDIRI
}

\author{
Zulkifli Musannip Efendi Siregar \\ Dosen Tetap Sekolah Tinggi Ilmu Ekonomi (STIE) Labuhanbatu
}

\begin{abstract}
ABSTRAK
Tujuan dari penulisanpaper ini adalah untuk mengetahui strategi human capital yang dilakukan oleh Bank Mandiri. Bank Mandiri sebagai perusahaan nasional yang memiliki reputasi yang sangat bagus dan berkinerja unggul menyadari betul bahwa human capital merupakan aset penting sehingga harus dikelola dengan baik. Strategi human capital Bank Mandiri tercantum dalam Human Capital Management Framework Bank Mandiri yaitu : 1) Organization Development, yaitu pengembangan organisasi yang efisien, efektif dan bersaing, 2) Capacity Fulfillment, yaitu pemenuhan Human Capital yang handal baik yang bersumber dari internal maupun eksternal, 3) Learning \& Development, yaitu pengembangan \& pembelajaran Human Capital untuk mendukung kebutuhan bisnis, 4) Employee Relations, yaitu membangun engagement dan hubungan industrial yang harmonis, 5) Rewards \& Performance Management, yaitu pengelolaan kinerja yang prima dan sistem imbalan yang kompetitif, dan 6) Talent dan Succession Management, yaitu penyediaan leadership pipeline dan pengelolaan suksesi.
\end{abstract}

Kata kunci : Strategi, Human Capital

\section{Pendahuluan}

Konsep human capital muncul,karena adanya pergeseran peranan sumber daya manusia.Human capital muncul dari pemikiran bahwa manusia merupakan asset yang memiliki banyak kelebihan yaitu kemampuan manusia apabila digunakan dan disebarkan tidak akan berkurang melainkan bertambah baik bagi individu yang bersangkutan maupun bagi organisasi, manusia mampu mengubah data menjadi informasi yang bermakna, manusia mampuberbagi intelegensia dengan pihak lain.

Human capital, bukanlah memposisikan manusia sebagai modal layaknya mesin, sehingga seolah-olah manusia sama dengan mesin, sebagaimana teori human capital terdahulu. Namun setelah teori ini semakin meluas, maka human capital justru bisa membantu pengambil keputusan untuk memfokuskan pembangunan manusia dengan menitikberatkan pada investasi pendidikan (termasuk pelatihan) dalam rangka peningkatan mutu organisasi sebagi bagian pembangunan bangsa. Penanganan SDM sebagai human capital menunjukkan bahwa hasil dari investasi non fisik jauh lebih tinggi dibandingkan investasi berupa pembangunan fisik.Human capital penting karena merupakan sumber inovasi dan pembaharuan strategi yang dapat diperoleh dari brainstorming melalui riset laboratorium, impian manajemen, process reengineering, dan perbaikan atau pengembangan ketrampilan pekerja. Selain itu, human capital memberikan nilai tambah dalam perusahaan setiap hari, melalui motivasi, komitmen, kompetensi serta efektivitas kerja tim. Nilai tambah yang dapat dikontribusikan oleh pekerja berupa: pengembangan kompetensi yang dimiliki oleh perusahaan, pemindahan pengetahuan dari pekerja ke perusahaan serta perubahan budaya manajemen (Mayo 2000 dalam Rachmawati et al. 2004).

Tahun 2013 merupakan tahun penuh tantangan karena perekonomian global tumbuh melambat seiring masih belum pulihnya perekonomian Amerika dan Eropa dan perlambatan 
pertumbuhan ekonomi China. Didalam negeri nilai tukar yang melemah cukup dalam, melebarnya defisit anggaran Pemerintah, serta likuiditas yang semakin ketat.

Beberapa indikator perekonomian mengalami tekanan diantaranya perlambatan pertumbuhan dari 6,2\% YoY di 2012, menjadi 5,8\% YoY di 2013 yang tidak terlepas dari pengaruh kebijakan stabilisasi oleh Pemerintah dan Bank Indonesia. Inflasi meningkat tajam hingga mencapai 8,38\% seiring kenaikan harga BBM bersubsidi, kenaikan UMP,

dan kenaikan TDL Listrik. Rupiah sepanjang tahun 2013 juga mengalami tekanan yang cukup tajam hingga 24,7\% menyentuh posisi Rp12.213/USD. Tekanan inflasi dan pelemahan Rupiah ini mendorong peningkatan BI Rate hingga mencapai level 7,5\%. Kenaikan BI Rate ini mendorong perbankan menaikkan suku bunga yang meningkat rata-rata menjadi 7,25\% dan kredit menjadi 12\%. (Sumber : Laporan tahunan Bank Mandiri Tahun 2013, hal 25)

Namun, tekanan eksternal yang cukup besar tersebut tidak menghentikan langkah Mandiri Group untuk terus memberikan kontribusi yang maksimal kepada mas yarakat luas dan komunitas, menciptakan berbagai inovasi baru untuk memakmurkan negeri. Pengalaman Mandiri Group yang tetap mampu menjaga momentum pertumbuhan menghadapi turbulensi perekonomian seperti di tahun 2005 dan 2008, juga telah menjadi modal bagi kami di tahun 2013 untuk tetap menjadi kebanggaan ibu pertiwi.

Di tataran domestik, tahun 2013 Mandiri Group mampu mempertahankan posisi sebagai lembaga keuangan yang terbesar di Indonesia dengan total aset mencapai Rp733,1 Triliun, mengelola lebih dari 14 juta rekening dana masyarakat. Mandiri Group juga telah bertransformasi menjadi lembaga keuangan yang handal dan terpercaya dengan berbagai prestasi pencapaian. Hal tersebut tercermin dari pertumbuhan tahunan dana murah sebesar 13,9\%, komposisi dana murah mencapai 64,7\%, pertumbuhan kredit mencapai 21,5\%, komposisi pembiayaan ritel mencapai lebih dari 31,2\%, serta laba bersih sebesar Rp18,2 Triliun atau tumbuh 17,4\% secara tahunan. Dari aspek market share, Bank Mandiri menguasai pangsa pasar terbesar untuk aset dan dana masyarakat di perbankan nasional masing-masing sebesar 15,2\% dan 15,6\%. (Sumber : Laporan tahunan Bank Mandiri Tahun 2013, hal 25).

Prestasi PT.Bank Mandiri tersebut tidak terlepas dari sumber daya manusia yang ada di dalam perusahaan tersebut. Karyawan atau human capital merupakan aset penting dalam sebuah perusahaan. PT. Bank mandiri menyadari sepenuhnya bahwa dengan melakukangan pengembangan human capital secara terencana dan berkesinambungan akan memberikan kontribusi yang besar bagi kinerja PT.Bank Mandiri itu sendiri. Human capital mencakup kecakapan karyawan itu sendiri, baik kecakapan intelegensial, karakter, motivasi maupun kreativitas karyawan itu sendiri. Sumber daya manusia memiliki peranan penting dalam memajukan organisasi. Hal ini sesuai dengan pendapata Fitz-Enz (2000:9) mendeskripsikan human capital sebagai kombinasi dari tiga faktor, yaitu: 1) karakter atau sifat yang dibawa ke pekerjaan, misalnya intelegensi, energi, sikap positif, keandalan, dan komitmen, 2) kemampuan seseorang untuk belajar, yaitu kecerdasan, imajinasi, kreativitas dan bakat, dan 3) motivasi untuk berbagi informasi dan pengetahuan, yaitu semangat tim dan orientasi tujuan.

Studi empiris oleh Endri Dalam jurnal Jurnal Administrasi Bisnis (2010), Vol.6, No.2: hal. 179-190,(ISSN:0216-1249)budaya organisasi2010Center for Business Studies. FISIP Unpar dengan judul Peran Human Capital Dalam Meningkatkan Kinerja Perusahaan memaparkan Studi-studi empiris tahun 1980-an memberikan hasil yang mixed terhadap hubungan antara human capital dengan kinerja perusahaan. Nkomo $(1986,1987)$ menguji hubungan antara perencanaan SDM dengan kinerja bisnis, dan menemukan tidak ada korelasi diantaranya. Hasil ini juga didukung oleh studi yang didasarkan atas survei (Delaney, Lewin and Ichniowski 1988, 1989) yang menyimpulkan tidak ada hubungan antara praktek SDM dengan kinerja keuangan perusahaan. Sementara studi-studi empiris tahun 1990-an sekarang lebih banyak membuktikan hubungan yang positif dan signifikan antara human capital dengan kinerja perusahaan. 


\section{Perumusan Masalah}

Dari latar belakang masalah, perumusan masalah dalam artikel ilmiah ini adalah bagaimana strategi Human Capital pada Bank Mandiri.

\section{Tujuan}

Sesuai dengan masalah yang telah dirumuskan, maka tujuan dilakukannya artikel ini adalah untuk mengungkapkan strategi Human Capital pada Bank Mandiri.

\section{Tinjauan Teorits}

\section{Pengertian Bank}

Berdasarkan Undang-Undang Republik Indonesia Nomor 10 Tahun 1998 tentang Perubahan Atas Undang-Undang Nomor 7 Tahun 1992 tentang Perbankan, bank adalah : "Badan usaha yang menghimpun dana dari masyarakat dalam bentuk simpanan dan menyalurkannya kepada masyarakat dalam bentuk kredit dan atau bentuk-bentuk lainnya dalam rangka meningkatkan taraf hidup rakyat banyak." Menurut Kasmir (2008:25) Bank adalah: "Lembaga keuangan yang kegiatan utamanya menerima simpanan giro, tabungan, dan deposito. Kemudian bank juga dikenal sebagai tempat untuk meminjam uang (kredit) bagi masyarakat yang membutuhkannya”.

\section{Pengertian Human Capital}

Stocey (2003) mendefinisikan pengertian human capital adalah "The term of human capital is recognition that people in organization and bisiness are an important an essential asset who contribute to development and growth, in a similar way as physical asset such as machines and money. The collective attitude, skill and abilities of people contribute to organization performance and productivity. Any expenditure in training, development, health and support is an investement not just an expense". Artinya bahwa human capital merupakan konsep menjelaskan bahwa manusia dalam organisasi dan bisnis merupakan aset yang penting dan beresensi, yang memiliki sumbangan terhadap pengembangan dan pertumbuhan, sama seperti halnya aset fisik misal mesin dan modal kerja. Sikap dan ketrampilan dan kemampuan manusia memiliki kontribusi terhadap kinerja dan produktivitas organisasi. Pengeluaran untuk pelatihan, pengembangan, kesehatan dan dukungan merupakan investasi dan bukan hanya biaya tapi merupakan investasi.

Menurut Moeheriono (2009), human capital tidak lain adalah sumber daya manusia yang dimiliki suatu organisasi atau perusahaan. Peranan sumber daya manusia diyakini oleh banyak kalangan merupakan asset terpenting bagi perusahaan karena keberhasilan perusahaan sangat tergantung kepada bagaimana perusahaan mengelola karyawannya.

Sumber daya insani merupakan sumber daya paling penting untuk dapat memenangkan persaingan, karena merupakan tulang punggung dari seluruh sistem yang dirancang,metode yang diterapkan, dan teknologi yang digunakan. Oleh karna itu, vital untuk mengembangkan sumber daya insani melalui proses rekrutmen yang kompetitif, pelatihan yang sistematis, peningkatan kepuasan pegawai, peningkatan pendidikan pegawai, dan pemberdayaan pegawai (Wibisono, 2006).

Mark L. Lengnick Hall (2003:45-46) menjelaskannya dengan mengutip beberapa pengertian human capital sebagai berikut:

a. Human capital is "the knowledge, skills and capabilities of individual that have economic value to an organization" (Bohlander, Snell \& Sherman, 2001)

b. Human capital is " the collective value of an organization's know-how. Human capital refers to the value, usually not reflected in accounting system, which results from the 
investment an organization must make to recreate the knowledge in its employee" (Cortada \& Woods, 1999)

c. Human capital is "all individual capabilities, the knowledge, skill, and experience of the company's employee and managers" (Edvinson \& Malone, 1997). Dari tiga pengertian di atas nampak sekali adanya kesamaan esensi yang menunjukkan bahwa modal manusia merupakan sesuatu yang melekat dalam diri invidivu. Hal yang menonjol dari defenisi atas adalah dimensi ekonomi yang menjadi acuan kebermanfaatnya.

\section{Komponen Human Capital}

Manusia adalah komponen yang sangat penting di dalam proses inovasi. Manusia dengan segala kemampuannya bila dikerahkan keseluruhannya akan menghasilkan kinerja yang luar biasa. Ada enam komponen dari modal manusia menurut Ancok 2002, yakni:
a. Modal intelektual
b. Modal emosional
c. Modal social
d. Modal ketabahan
e. Modal moral
f. Modal kesehatan

Keenam komponen modal manusia ini akan muncul dalam sebuah kinerja yang optimum apabila disertai oleh modal kepemimpinan dan modal struktur organisasi yang memberikan wahana kerja yang mendukung(Ancok, 2002).

\section{Pembahasan}

Sumber Daya Manusia (SDM) adalah faktor sentral dalam suatu organisasi. Apapun bentuk serta tujuannya, organisasi dibuat berdasarkan berbagai visi untuk kepentingan manusia dan dalam pelaksanaan misinya dikelola dan diurus oleh manusia. Jadi, manusia merupakan faktor strategis dalam semua kegiatan institusi/organisasi. Selanjutnya, MSDM berarti mengatur, mengurus SDM berdasarkan visi perusahaan agar tujuan organisasi dapat dicapai secara optimum.

Berdasarkan data yang ada pada Laporan Tahunan Bank mandiri Tahun 2013, penulis melihat bahwa PT. Bank Mandiri memiliki human capital atau jumlah karyawan yang terus bertambah dan terus mengalami pertumbuhan dari tahun ke tahun. Untuk lebih jelasnya dapat dilihat pada gambar dibawah ini :

Tabel 1

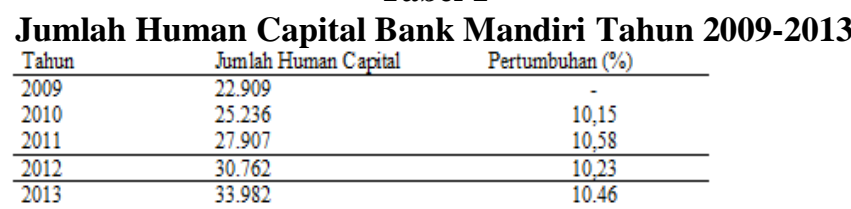

Sumber : Annual Report Bank Mandiri Tahun 2013

Berdasarkan data di atas, jumlah karyawan atau human capital bank mandiri memiliki perkembangan yang begitu pesat dari tahun ketahun. Tahun 2009 jumlah karyawan Bank 
Mandiri sebanyak 22.909, pada tahun 2010 menjadi sebanyak 25.236 atau tumbuh sebesar 10.15\%, pada tahun 2011 karyawan Bank Mandiri berjumlah 27.907 atau tumbuh sebesar 10,58\%, pada tahun 2012 karyawan bank mandiri berjumlah 30.762 atau tumbuh sebesar 10,23\%, pada tahun 2013 jumlah karyawan bank mandri sebanyak 33.982 atau tumbuh sebanyak $10,46 \%$.

Dari segi pertumbuhan human capital atau karyawan Bank Mandiri dari tahun ke tahun mengalami pertumbuhan yang relatif stabil dan tidak terjadi fluktuasi jumlah karyawan. Hal ini menunjukkan bahwa turnover pada Bank Mandiri boleh dikatakan sangat kecil bahkan bias dijustifikasi tidak ada turnover. Pertumbuhan human capital diiringi juga dengan pertumbuhan jumlah kantor cabang PT. Bank Mandiri di berbagai daerah. Cabang Bank Mandiri terus mengalami pertumbuhan dari tahun ke tahun hal ini dapat dilihat pada Tabel berikut ini :

Tabel 2

Pertumbuhan Kantor Cabang PT.Bank Mandiri Tahun 2009-2013

\begin{tabular}{llc} 
Tahrur & Jurilah Kantor Cabang & Pertumbutan $(\%)$ \\
\hline 2009 & 1092 & - \\
2010 & 1370 & 12.19 \\
2011 & 1537 & 17.76 \\
\hline 2012 & 1810 & 13.26 \\
\hline 2013 & 2050 & 25.11
\end{tabular}

Sumber : Annual Report Bank Mandiri Tahun 2013

Bank Mandiri sebagai perusaaan besar tentu sangat paham agar mengelola karyawan dengan cara yang baik dan benar sehingga memberikan kinerja yang bagus terhadap perusahaan. Hal ini juga tertuang dalam Misi Bank Mandiri, diantaranya adalah:

Misi Bank Mandiri:

1. Diarahkan untuk memenuhi kebutuhan pasar

2. Pengembangan sumber daya manusia professional

3. Memberikan manfaat maksimal kepada para pemangku kepentingan

4. Untuk mengelola pelaksanaan terbuka

5. Perawatan untuk kepentingan masyarakat dan lingkungan

Bank Mandiri terus melakukan transformasi di bidang human capital melalui akselerasi human capital value creation dan pengembangan strategi serta kebijakan yang mendukung perubahan Bank Mandiri dari Good Companymenjadi Great Company.Di tahun 2013 pengelolaan human capital di Bank Mandiri difokuskan pada peningkatan kualitas human capitaluntuk mendorong peningkatan kinerja Bank Mandiri dari waktu ke waktu.

Program Human Capitaldisusun dengan tema "Aligning Human Capital Management System toward Best in Class Practices based onEmployee Value Proposition”. Bank Mandiri telah memiliki Employee Value Proposition (EVP) yang menjadi noble purpose (tujuan mulia) bagi pegawai yang bekerja di Bank Mandiri. Mandiri EVP dibangun berdasarkan aspirasi 
pegawai, yang menyatukanapa yang menjadi aspirasi pegawai dengan apa yang diberikan perusahaan.

Mandiri EVP menggambarkan "What it means to be a Mandirian". Makna yang terkandung dalam Spirit Memakmurkan Negeri adalah, "Di Mandiri, kita memiliki Spirit Memakmurkan Negeri, yang menjadikan kita berkembang dalam lingkungan yang terbuka, positif dan progresif, untuk menciptakan kemakmuran bagi rekan kerja, keluarga, nasabah, masyarakat dan Indonesia".

Mandiri EVP akan memberikan nilai tambah bagi perusahaan yakni meningkatnya level of engagement pegawaimaupun para nasabah Bank Mandiri, memiliki daya saing yang tinggi untuk meng-attract dan mendapatkankandidat top talent di market, memiliki kemampuan mempertahankan top talent untuk tetap berkarir di BankMandiri, mengurangi tingkat turn-over pegawai, meningkatkan image dan reputasi Bank sebagai employer of choice dan pada akhirnya meningkatkan intangible asset perusahaan dari waktu ke waktu. Dari sisi pegawai, Mandiri EVP akan memberikan arti bagi pegawai yang merasakan sebagai bagian yang pentingdari organisasi, merasakan setiap peran atau tugas yang diemban memberikan kontribusi bagi kemajuanorganisasi, nasabah, keluarga, masyarakat dan Indonesia, memiliki kesempatan untuk mengaplikasikan keahlianterbaik yang dimiliki dan mengembangkan diri secara individu dan profesional serta pegawai akan mendapatkan

reward sesuai dengan kompetensi dan kinerjanya.

Bank Mandiri menyadari bahwa untuk mewujudkan visi Bank Mandiri 2010-2014 yakni menjadi lembaga keuangan Indonesia yang paling dikagumi dan selalu progresif, tidak cukup hanya memperkuat aspek finansial saja tetapi juga dari aspek non-finansial melalui pengelolan kapabilitas human capital (people is the power behind our purpose). Strategi pengelolaan Human Capital dilaksanakan dengan memperhatikan prinsip kehati-hatian, penerapan manajemen risiko, GCG dan effective best in class \& innovative practices serta selaras dengan Employee Value Proposition, Spirit Memakmurkan Negeri atau Prosperous Spirit.

Strategi di bidang Human Capital telah diselaraskan dengan strategi Bank Mandiri, yang difokuskan pada seluruh value chain pengelolaan Human Capital (employee lifecycle). Tahapan dalam employee lifecycle dimulai dari pengembangan organisasi (organization development), pemenuhan Human Capital (capacity fulfillment), pengembangan Human Capital (learning \& development), pengelolaan hubungan kepegawaian (employee relations), pengelolaan kinerja dan sistem imbalan (rewards \& performance management) sampai dengan pengelolaan talent dan suksesi (talent \& succession management). Pada setiap tahapan dalam employee lifecycle dimaksud dibangun 2 (dua) hal untuk meyakini penerapan yang berkesinambungan yaitu:

1.Membangun budaya dan kepemimpinan yang menunjang transformasi, termasuk perubahan mindset danperilaku, serta peningkatan peran leaders dalam proses pengelolaan Human Capital (Culture \& Leadership)

2.Membangun strategi dan taktik penerapan, termasuk kebijakan, proses, kemampuan pegawai dan teknologi pendukung (Strategic \& Tactical HC Practices).

Fungsi-fungsi utama sebagai tahapan dalam Human Capital Management Framework Bank Mandiri adalah sebagai berikut:

1.Organization Development, yaitu pengembangan organisasi yang efisien, efektif dan bersaing

2.Capacity Fulfillment, yaitu pemenuhan Human Capital yang handal baik yang bersumber dari internal maupun eksternal.

3.Learning \& Development, yaitu pengembangan \& pembelajaran Human Capital untuk mendukung kebutuhan bisnis 
4.Employee Relations, yaitu membangun engagement dan hubungan industrial yang harmonis 5.Rewards \& Performance Management, yaitu pengelolaan kinerja yang prima dan sistem imbalan yang kompetitif

6. Talent dan Succession Management, yaitu penyediaan leadership pipeline dan pengelolaan suksesi.

\section{Pengembangan Organisasi, Karir dan Waktu Kerja yang Fleksible (Organization Development)}

Dalam rangka mendukung pertumbuhan bisnis, diperlukan organisasi yang efisien, efektif dan mampu bersaing di market. Untuk itu, pengembangan organisasi difokuskan kepada organization review dengan melakukan kajian terhadap produktifitas dan efektifitas struktur organisasi, menyiapkan job kompetensi untuk mempercepat pengembangan karir pegawai serta menyusun dan mengimplementasikan flexible time atau biasa disebutFlexitime secara bertahap. Implementasi Flextime ini untuk memfasilitasi pegawai dalam mengelola jam kerjanya secara optimal baik untuk kepentingan Bank maupun kepentingan pribadi tanpa mengganggu layanan/kelancaran operasional bisnis Bank dan bekerja sesuai dengan total jam yang ditentukan dalam periode tertentu.

\section{Kesempatan Bekerja, Berkembang dan Maju bersama (Capacity Fullfillment)}

Pertumbuhan bisnis yang sangat cepat perlu didukung dengan strategi pemenuhan pegawai yang tepat dan akurat dengan mengacu pada prinsip "right people with potential right fit". Kebijakan pemenuhan pegawai selalu disesuaikan dengan kebutuhan bisnis dari waktu ke waktu Kebutuhan pegawai tersebar di unit-unit seluruh Indonesia dan untuk membuka peluang kepada putera-puteri daerah terbaik yang tersebar dari Sabang sampai Merauke untuk bekerja di Bank Mandiri, perekrutan dilakukan bekerja sama dengan berbagai perguruan tinggi terkemuka di Indonesia melalui keikutsertaan dalam kegitan job fair/bursa kerja maupun penyelenggaraan campus hiring. Selain itu, upaya pencarian kandidat dilakukan menggunakan media e-Recruitment melalui website Bank Mandiri (www.bankmandiri.co.id).

Strategi Pemenuhan pegawai di Bank Mandiri dilakukan dari 2 (dua) cara, yakni:

1. Internal resources yakni melalui program pengembangan internal pegawai : Staff Development Program (SDP), Local Staff Development Program (LSDP), Pegawai Pelaksana Pemegang Kewenangan (P3K), Program Pendidikan Pimpinan Muda Mikro (PPMM), dan perpindahan pegawai pelaksana dari Front Office ke Back Office.

2. External resources yakni melalui jalur fresh graduate dan experience hire baik untuk level pegawai pimpinan maupun pelaksana. Pemenuhan pegawai melalui external resources tersebut dilakukan dengan memperhatikan hal-hal dan kondisi khusus baik yang menyangkut kelangkaan resources pegawai pimpinan di daerah tertentu, jenis pekerjaan maupun expertise-nya, sebagai berikut:

\section{Kesimpulan}

Strategi human capital Bank Mandiri tercermin dalam Human Capital ManagementFramework Bank Mandiri yaitu 1) Organization Development, yaitu pengembangan organisasi yang efisien, efektif dan bersaing, 2) Capacity Fulfillment, yaitu pemenuhan Human Capital yang handal baik yang bersumber dari internal maupun eksternal, 3) Learning \& Development, yaitu pengembangan \& pembelajaran Human Capital untuk mendukung kebutuhan bisnis, 4) Employee Relations, yaitu membangun engagement dan hubungan industrial yang harmonis, 5) Rewards \& Performance Management, yaitu 
pengelolaan kinerja yang prima dan sistem imbalan yang kompetitif, dan 6) Talent dan Succession Management, yaitu penyediaan leadership pipeline dan pengelolaan suksesi.

\section{Saran}

Strategi Human Capital Bank Mandiri sudah sangat baik, perlu dipertahankan dan ditingkatkan lagi dan diimplementasikan dengan sungguh-sungguh.

\section{Daftar Pustaka}

Hall, Mark L.Lengnick dan Cynthia A. 2003. Human ResourceManagement in the Knowledge Economy, Berret Koehler

Kasmir,2008. Bank dan Lembaga Keuangan Lainnya. Edisi Revisi. PT Rajagrafindo. Persada, Jakarta

Laporan Tahunan Bank Mandiri 2013

Moeheriono. 2009. Pengukuran Kinerja Berbasis Kompetensi. Ghalia Indonesia. Bogor.

Stocey .(2000) Human capital A Self Assestment Checklist For Agency Leader office of the Controller General

Undang-Undang Republik Indonesia Nomor 10 Tahun 1998 tentang Perubahan Atas

Undang-Undang Nomor 7 Tahun 1992 tentang Perbankan,

Wibisono, D. 2006. Manajemen Kinerja Konsep, Desain, dan Tekhnik Meningkatkan Daya Saing Perusahaan. Gelora Aksara Pratama. Bandung 